\title{
C-reactive protein as a predictor of prognosis following curative resection for colorectal liver metastases
}

\author{
VKH Wong', HZ Malik', ZZR Hamady', A Al-Mukhtar', D Gomez', KR Prasad', GJ Toogood' and JPA Lodge*,I \\ 'HPB and Transplant Unit, St. James's University Hospital, Leeds LS9 7TF, UK
}

\begin{abstract}
There is increasing evidence that systemic inflammatory response has a positive correlation with a poorer outcome in patients undergoing resection for solid tumours. The aim of this study was to analyse the impact of an elevated C-reactive protein (CRP), an outcome following curative resection for colorectal liver metastases. One hundred and seventy patients who underwent curative resection for colorectal liver metastases were included in the study. Laboratory measurements of haemoglobin, white cell, platelets, albumin and CRP were taken on the day before surgery. Elevated CRP $\left(>10 \mathrm{mgl}^{-1}\right)$ was present in 54 (31.8\%) patients. The median survival of patients with an elevated CRP was 19 months ( $95 \% \mathrm{Cl} 7.5-31.2$ months) compared to 42.8 months ( $95 \% \mathrm{Cl} 33.2-52.5$ months) for those with a normal CRP, $P=0.004$. Similarly, when assessing disease-free survival, patients with an elevated CRP had

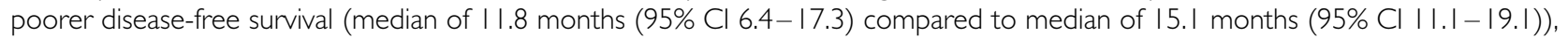
$P=0.043$. The result of the study showed that an elevated preoperative CRP is a predictor of poor outcome in patients undergoing curative resection for colorectal liver metastases.
\end{abstract}

British Journal of Cancer (2007) 96, 222-225. doi:I0.1038/sj.bjc.6603558 www.bjcancer.com

Published online 9 January 2007

(c) 2007 Cancer Research UK

Keywords: C-reactive protein; colorectal liver metastases; inflammatory response; survival

Colorectal cancer is the third commonest malignancy in UK with around 32000 people diagnosed with colorectal cancer each year (Cancerstats, 2003; www.cancerresearchuk.org). Of that, around $20-25 \%$ of patients will have liver metastases (CRLM) at presentation and a further $40-50 \%$ will develop metachronous CRLM following colorectal surgery. Over the last two decades, liver resection has been established as the standard therapy for CRLM and offers the best chance of a potential cure with a 5-year survival of over $40 \%$ (Finch et al, 2006; Simmonds et al, 2006). However, disease recurrence is common with about two-thirds of patients who had liver resection for CRLM developing recurrent disease, and half of these patients had the disease recur in the remnant liver (Steele et al, 1991; Nordlinger et al, 1994; Fong et al, 1997; Hamady et al, 2006).

Several studies have looked for possible prognostic factors indicating poor survival outcome and disease recurrence after initial liver resection for CRLM (Fong et al, 1999; Seifert et al, 2000; Takahashi et al, 2003; Tanaka et al, 2004; Hamady et al, 2006). Primary colorectal adenocarcinoma stage and grade, size, distribution and number of liver metastases, presence of extrahepatic disease, resection margins and lymph nodes status are among the potential prognostic factors but to date, no consensus have been reached.

Recently, there is increasing evidence that inflammation, both local and systemic, has a causal link in the pathogenesis of many solid tumours (Balkwill and Mantovani, 2001; Coussens and Werb,

*Correspondence: Dr JPA Lodge;

E-mail: Peter.Lodge@leedsth.nhs.uk

Received 4 October 2006; revised 23 November 2006; accepted 23

November 2006; published online 9 January 2007
2002). Infiltration of proinflammatory macrophages, cytokines and chemokines in the tumour microenvironment predispose the tumour to further progression, growth, invasion and metastasis. Gunter et al (2006) showed an association between chronic lowgrade inflammation, as evidenced by elevated C-reactive protein (CRP), with an increased risk of colorectal cancer. In addition, raised CRP is associated with an increased risk of developing early recurrence and poor outcome following colorectal surgery (McMillan et al, 1995, 2003; Canna et al, 2005). This suggests that it is not only the intrinsic properties of tumour cells that determine invasion and metastasis, but also the tumour microenvironment.

The aim of this study is to examine the relationship between inflammation, as evidenced by elevated CRP measured before surgery and outcome in patients who had liver resection for CRLM.

\section{MATERIALS AND METHODS}

Patients undergoing resection for colorectal liver metastases had CRP measured preoperatively. CRP (reference range being $10 \mathrm{mgl}^{-1}$ or less) measurements were taken on the day before surgery with none of the patients showing clinical signs of sepsis. The criteria for acceptance for surgery included fitness for major resection and lack of disseminated or irresectable extrahepatic disease identified by computerised tomography (CT) or MRI scan. In all cases, the colorectal primary had been previously resected and the patients had recovered fully from that procedure. Patients who underwent neo-adjuvant therapy were excluded from this study. Intraoperative ultrasound was used as an adjunct to the preoperative radiological investigations. Resection was performed using the Cavi-Pulse Ultrasonic Surgical Aspirator (CUSA, Model 
200 T, Valley Lab., Boulder, CO, USA). If necessary, an intermittent Pringle manoeuvre was used with $15 \mathrm{~min}$ of ischaemia followed by 5 min of reperfusion.

In accordance with our unit protocol, all patients undergoing liver resection were offered adjuvant therapy in the form of 5-FU/ folinic acid, unless they had received adjuvant therapy following their colonic resection within the past one year.

Patients were followed up at specialist clinics, with a minimum follow-up period of 1 year at the time of writing (range 1-5 years; median 28 months). No patients were lost to follow-up. An intensive policy of postoperative surveillance exists within this unit. Patients have three monthly chest and abdominal CT performed during the first postoperative year, then 6 monthly during year 2. From year 3 to 5 , a CT scan is performed yearly and finally at year 7 and year 10 of follow-up. Tumour markers carcinoembryonic antigen ((CEA), CA19-9) and liver function tests are performed during each clinic visit. The data examined included patient demographics; liver resection histology; prehepatectomy CEA and CA19-9 tumour marker; prehepatectomy CRP; postoperative morbidity/mortality results as well as recurrence and survival figures.

\section{STATISTICS}

An SPSS version 9 statistical programme was used to analyse the data. The Student's $t$-test and $\chi^{2}$ tests were used to analyse differences among groups of patients with high or normal CRP. Where variables did not follow a normal distribution, the MannWhitney test was applied. Kaplan-Meier survival curves were used to analyse patient outcome. Patients who died in the postoperative period were excluded from the analysis of outcome. A Cox regression analysis was then performed in a step-wise manner in order to perform a multivariable analysis of clinico-pathological factors that impact both overall and disease-free survival.

\section{RESULTS}

A total of 170 patients were included in this study. Of these patients, $106(62 \%)$ were males and $64(38 \%)$ females. The mean age of patient at time of surgery was 64 years (range 37-87 years; s.d. 9.86 years). A total of $86(50.6 \%)$ patients had synchronous disease. All patients underwent liver resection. There were 76 $(44.7 \%)$ patients who underwent an anatomical resection, a further $45(26.5 \%)$ patients underwent a combination of anatomical and nonanatomical resection whereas the remaining $49(28.8 \%)$ patients underwent a nonanatomical resection. A total of $57 \%$ of patients had a 'major' (three or more Couinaud segments) resection performed. The in-hospital mortality rate was $3 \%$ and $29(17 \%)$ patients had postoperative complications.

Preoperative CRP was elevated $\left(>10 \mathrm{mgl}^{-1}\right)$ in $54(31.8 \%)$ patients. The differences in the clinico-pathological features of patients with a normal compared to an elevated CRP are presented in Table 1. Of note is that patients with an elevated CRP had no significant differences in the ' $\mathrm{T}$ ' or ' $\mathrm{N}$ ' stage of the primary tumour. However, patients with an elevated CRP tended to have larger metastases as well as increased CA19-9 levels compared to those with normal CRP.

\section{Outcome}

Overall there were $80(47 \%)$ patients who died during the time period of this study. Of these, there were six non-cancer-related deaths. Thus, the cancer-specific survival was $56 \%$. The median survival of patients with an elevated CRP was 19 months (95\% CI 7.5-31.2 months) compared to 42.8 months (95\% CI 33.2-52.5 months) for those with a normal CRP, $P=0.004$ (Figure 1). Similarly, when assessing disease-free survival, patients with an
Table I Clinico-pathological features

\begin{tabular}{|c|c|c|c|}
\hline Factor & $\begin{array}{l}\text { Normal CRP } \\
\left(10 \mathrm{mg} \mathrm{I}^{-1} \text { or }\right. \\
\text { less })(\mathrm{N}=116)\end{array}$ & $\begin{array}{c}\text { Elevated CRP } \\
\left(>10 \mathrm{mg} \mathrm{I}^{-1}\right) \\
(\mathrm{N}=54)\end{array}$ & Significance \\
\hline Age (mean) & 63.7 & 64.7 & 0.577 \\
\hline Synchronous disease & 56 & 30 & 0.502 \\
\hline Male gender & 73 & 33 & 0.802 \\
\hline $\begin{array}{l}\text { Multiple ( } 4 \text { or more) } \\
\text { metastases }\end{array}$ & 27 & 12 & 0.568 \\
\hline \multicolumn{4}{|l|}{ Primary nodal status } \\
\hline No & 32 & 10 & 0.371 \\
\hline $\mathrm{NI}$ & 51 & 27 & \\
\hline N2 & 9 & 6 & \\
\hline \multicolumn{4}{|l|}{ Primary $T$ stage } \\
\hline TI & I & 3 & 0.111 \\
\hline $\mathrm{T} 2$ & 8 & 3 & \\
\hline T3 & 57 & 19 & \\
\hline $\mathrm{T} 4$ & 24 & 15 & \\
\hline CEA & 61.5 & 63 & 0.820 \\
\hline CA19-9 & 53.9 & 70.9 & 0.013 \\
\hline $\begin{array}{l}\text { Large metastases size } \\
(>50 \mathrm{~mm})\end{array}$ & 34 & 31 & 0.003 \\
\hline Positive margin & 23 & 15 & 0.641 \\
\hline
\end{tabular}

$\mathrm{CEA}=$ carcinoembryonic antigen; $\mathrm{CRP}=\mathrm{C}$-reactive protein. Mann-Whitney U-test.

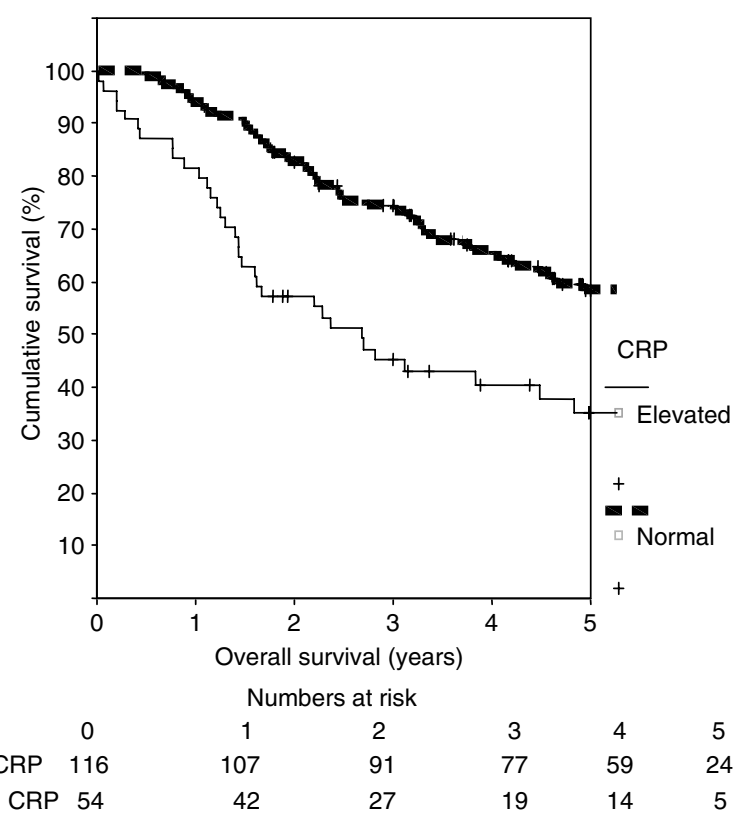

$P=0.004$

Figure I Overall survival stratified according to CRP.

elevated CRP had poorer disease-free survival (median of 11.8 months (95\% CI 6.4-17.3) compared to median of 15.1 months (95\% CI 11.1-19.1)), $P=0.043$ (Figure 2). The results of univariate and multivariable analysis of the predictors of overall survival are shown in Tables 2 and 3, respectively. Of note is the fact that an elevated CRP was the only predictor of poor survival on univariate analysis. However on multivariable analysis, an elevated CRP as well as primary ' $\mathrm{T}$ ' stage both predicted for poorer overall survival. When the multivariable analysis was repeated for disease-free 


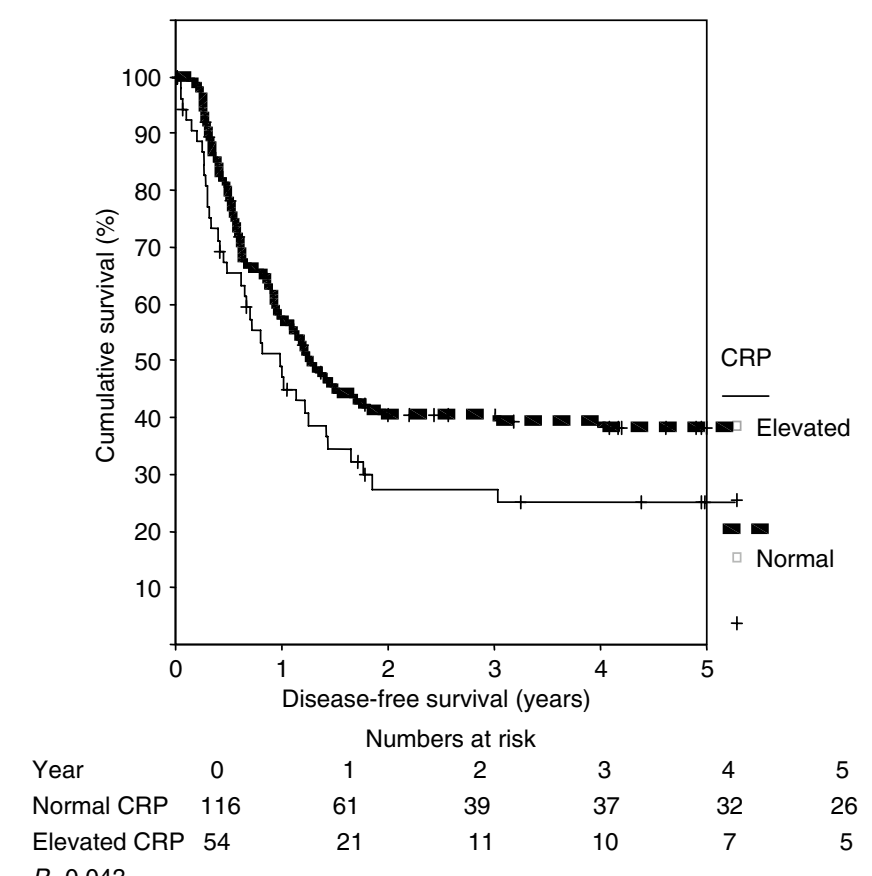

$P=0.043$

Figure 2 Disease-free survival stratified according to CRP.

Table 2 Univariate analysis of overall survival

\begin{tabular}{lr}
\hline Factor & P-value \\
\hline Older age (years) & 0.536 \\
Gender (males) & 0.522 \\
CEA & 0.353 \\
CAI9-9 & 0.838 \\
Large $(>50 \mathrm{~mm})$ & 0.661 \\
metastases size & \\
Positive resection & 0.461 \\
Margin & \\
Synchronous & 0.309 \\
disease & \\
Primary tumour & 0.754 \\
nodal positivity & \\
Poorer tumour & 0.124 \\
primary T-stage & \\
Multiple (4 or more) & 0.244 \\
Metastases & \\
Poor clinical risk score & 0.972 \\
Elevated CRP & $<0.001$
\end{tabular}

$\mathrm{CEA}=$ carcinoembryonic antigen; $\mathrm{CRP}=\mathrm{C}$-reactive protein. $\mathrm{MSKCC}$ clinical risk score - poor scores defined as scores 3-5 (Fong et al, 1999).

survival, only the presence of an elevated CRP predicted for poorer outcome, $P=0.011$ (HR 4.07; 95\% CI 1.36-12.19).

\section{DISCUSSION}

Tumour progression is a complex process that depends not only on the intrinsic properties of the tumour, but also on its interaction with the host cells. Although the link between inflammation and cancer was first proposed by Virchow in 1863 , it is only in last two decades that we are beginning to delineate and have an understanding of this intricate network of interactions.
Table 3 Multivariable analysis of overall survival

\begin{tabular}{|c|c|c|c|}
\hline \multirow{2}{*}{$\frac{\text { Factor }}{\text { Older age (years) }}$} & \multicolumn{2}{|c|}{$\begin{array}{c}\text { Hazard ratio ( } 95 \% \text { confidence } \\
\text { interval) }\end{array}$} & \multirow{2}{*}{$\frac{P \text {-value }}{0.051}$} \\
\hline & 1.04 & $1.00-1.09$ & \\
\hline Gender (males) & 1.09 & $0.51-2.32$ & 0.816 \\
\hline CEA & 0.99 & $0.99-1.00$ & 0.785 \\
\hline CA19-9 & 0.99 & $0.99-1.00$ & 0.766 \\
\hline $\begin{array}{l}\text { Large }(>50 \mathrm{~mm}) \\
\text { metastases size }\end{array}$ & 0.99 & $0.97-1.01$ & 0.827 \\
\hline $\begin{array}{l}\text { Positive resection } \\
\text { Margin }\end{array}$ & 0.56 & $0.11-2.86$ & 0.488 \\
\hline $\begin{array}{l}\text { Synchronous } \\
\text { disease }\end{array}$ & 0.92 & $0.43-1.95$ & 0.836 \\
\hline $\begin{array}{l}\text { Primary tumour } \\
\text { nodal positivity }\end{array}$ & 0.60 & $0.30-1.19$ & 0.149 \\
\hline $\begin{array}{l}\text { Poorer tumour } \\
\text { primary T-stage }\end{array}$ & 1.82 & $1.10-3.00$ & 0.019 \\
\hline $\begin{array}{l}\text { Multiple ( } 4 \text { or more) } \\
\text { Metastases }\end{array}$ & 2.06 & $0.91-4.66$ & 0.785 \\
\hline $\begin{array}{l}\text { Poor clinical risk } \\
\text { score }\end{array}$ & 0.707 & $0.21-2.61$ & 0.747 \\
\hline Elevated CRP & 2.86 & $1.09-7.49$ & 0.032 \\
\hline
\end{tabular}

$\mathrm{CEA}=$ carcinoembryonic antigen; $\mathrm{CRP}=\mathrm{C}$-reactive protein. $\mathrm{MSKCC}$ clinical risk score- poor scores defined as scores 3-5 (Fong et al, 1999).

This study showed that elevated preoperative CRP present in almost one-third of patients with CRLM and is associated with a poor overall as well as disease-free survival in patients who had liver resection for colorectal metastases. This is consistent with other studies that found a positive correlation between elevated CRP concentrations, before surgery and a poor outcome in patients who had curative primary tumour resection (Nozoe et al, 2001; McMillan et al, 2003; Canna et al, 2005; Crumley et al, 2006). However, this is the first study to identify such a relationship among patients who have undergone curative resection for CRLM. This finding has important implications for selection of patients for surgery and the presence of an elevated CRP should be considered when counselling patients upon the likelihood of a 'curative resection'.

We also found that elevated CRP was associated with presence of larger metastases size and elevated CA19-9. It is possible that any impact upon survival of an elevated CRP may be as a result of this association. However, as neither of these factors were independent predictors of survival on multivariable analysis, it appears that the elevated CRP is the main factor contributing to the poorer outcome among these patients. Interestingly, there was no association between ' $\mathrm{T}$ ' and ' $\mathrm{N}$ ' characteristics of the primary and an elevation in CRP.

The basis for the relationship between elevated CRP and poor prognosis is unclear and there are several possible explanations. Elevated CRP level may simply reflect a nonspecific inflammatory response to tumour necrosis or local tissue damage. Alternatively, it may be indicative of a favourable environment for the establishment and growth of distant metastases. Serum level of vascular endothelial growth factor (VEGF), an angiogenic factor, is increased in the presence of raised CRP concentration (Xavier et al, 2006). Angiogenesis plays an important role in tumour growth and is associated with a poor outcome in patients with GI tumours (Tanigawa et al, 1997; Fondevila et al, 2004). In addition, interleukin (IL) -1 and -6 network is upregulated (Vidal-Vanaclocha et al, 2000; Miki et al, 2004). Interleukin 1 is involved in the development of metastasis in animal studies and IL-6, apart from being a growth factor, promotes resistance to apoptosis (Vidal-Vanaclocha et al, 1994, 2000; Chauhan et al, 1997; Frassanito et al, 2001; Jee et al, 2001). This creates a microenvironment that favours tumour angiogenesis, proliferation, growth and metastases. 
Host immune response plays a role in the evolution of tumour growth. An impaired host immune response, evidenced by a weak lymphocyte infiltration at tumour margin, is associated with a poor prognosis in patients who had liver resection for CRLM (Okano et al, 2003). There is an inverse relationship between CRP levels and tumour lymphocyte infiltration, with a raised CRP concentration indicative of a weak infiltration of lymphocytes at the periphery of the tumour (Canna et al, 2005). The significance of systemic inflammatory response in the pathogenesis of cancer has important clinical implications.

\section{REFERENCES}

Balkwill F, Mantovani A (2001) Inflammation and cancer: back to Virchow? Lancet 357: $539-545$

Cancer Research UK Information Centre (2003) CancerStats. http// :info.cancerresearchuk.org/cancerstats

Canna K, McArdle PA, McMillan DC, McNicol A-M, Smith GW, McKee RF, McArdle CS (2005) The relationship between tumour T-lymphocyte infiltration, the systemic inflammatory response and survival in patients undergoing curative resection for colorectal cancer. $\mathrm{Br} J$ Cancer 92: $651-654$

Chauhan D, Kharbanda S, Ogata A, Urashima M, Teoh G, Robertson M, Kufe DW, Anderson KC (1997) Interleukin-6 inhibits Fas-induced apoptosis and stress-activated protein kinase activation in multiple myeloma cells. Blood 89(1): $227-234$

Coussens LM, Werb Z (2002) Inflammation and cancer. Nature 420: $860-867$

Crumley ABC, McMillan DC, McKernan M, Going JJ, Shearer CJ, Stuart RC (2006) An elevated C-reactive protein concentration, prior to surgery, predicts poor cancer-specific survival in patients undergoing resection for gastro-oesophageal cancer. Br J Cancer 94: 1568 - 1571

Finch RJB, Malik HZ, Hamady ZZR, Al-Mukhtar A, Adair R, Prasad KR, Lodge JPA, Toogood GJ (2006) Outcome following liver resection for colorectal liver metastases: effect of type of resection. Br J Surg (in press)

Fondevila C, Metges JP, Fuster J, Grau JJ, Palacin A, Castells A, Volant A, Pera M (2004) p53 and VEGF expression are independent predictors of tumour recurrence and survival following curative resection of gastric cancer. Br J Cancer 90: 206-215

Fong Y, Cohen AM, Fortner JG, Enker WE, Turnbull AD, Coit DG, Marrero AM, Prasad M, Blumgart LH, Brennan MF (1997) Liver resection for colorectal metastases. J Clin Oncol 15: $938-946$

Fong Y, Fortner J, Sun RL, Brennan MF, Blumgart LH (1999) Clinical score for predicting recurrence after hepatic resection for metastatic colorectal cancer: analysis of 1001 consecutive cases. Ann Surg 230: 309-318

Frassanito MA, Cusmai A, Iodice G, Dammaco F (2001) Autocrine interleukin-6 production and highly malignant multiple myeloma: Relation with resistance to drug-induce apoptosis. Blood 97: 483-489

Gunter MJ, Stolzenberg-Solomon R, Cross AJ, Leitzmann MF, Weinstein S, Wood RJ, Virtamo J, Taylor PR, Albanes D, Sinha R (2006) A prospective study of serum C-reactive protein and colorectal cancer risk in men. Cancer Res 66: 2483-2487

Hamady ZZR, Cameron IC, Wyatt J, Prasad RK, Toogood GJ, Lodge JPA (2006) Resection margin in patients undergoing hepatectomy for colorectal liver metastasis: A critical appraisal of the $1 \mathrm{~cm}$ rule. Eur $J$ Surg Onco 32: $557-563$

Jee SH, Shen SC, Chiu HC, Tsai WL, Kuo M (2001) Overexpression of interleukin- 6 in human basal cell carcinoma cell lines increases antiapoptotic activity and tumorigenic potency. Oncogene 20: 198-208

McMillan DC, Canna K, McArdle CS (2003) Systemic inflammatory response predicts survival following curative resection of colorectal cancer. Br J Surg 90: 215-219

McMillan DC, Wotherspoon HA, Fearon KC, Sturgeon C, Cooke TG, McArdle CS (1995) A prospective study of tumor recurrence and the acute-phase response after apparently curative colorectal cancer surgery. Am J Surg 170: 319-322

Miki C, Konishi N, Ojima E, Hatada T, Inous Y, Kusunoki M (2004) $\mathrm{C}$-reactive protein as a prognostic variable that reflects uncontrolled
Several novel therapies targeting the inflammatory pathways are in clinical trial (Balkwill and Mantovani, 2001). Tumour necrosis factor (TNF) antagonists, chemokine and IL-6 antagonism, nonsteroidal anti-inflammatory agents and statin drugs are among the potential therapies. Selective Cox-2 inhibitors were of particular interest with promising initial results but adverse cardiovascular risks have limited their usage (Mukherjee et al, 2001; Thun et al, 2002; Yau et al, 2003).

In summary, the results of this study showed that elevated CRP levels, measured before surgery, are present in a significant proportion of patients with CRLM. This is found to predict for a poor survival outcome in patients who had liver resection performed.

up-regulation of the IL-1 - IL-6 network system in colorectal carcinoma. Dig Dis Sci 49: 970 - 976

Mukherjee D, Nissen SE, Topol EJ (2001) Risk of cardiovascular events associated with selective COX-2 inhibitors. JAMA 286: 954-959

Nordlinger B, Vaillant JC, Guiguet M, Balladur P, Paris F, Bachellier P, Jaeck D (1994) Survival benefit of repeat liver resections for recurrent colorectal metastases: 143 cases. Association Francaise de Chirurgie.. J Clin Oncol 12: 1491 - 1496

Nozoe T, Saeki H, Sugimachi K (2001) Significance of preoperative elevation of serum C-reactive protein as an indicator of prognosis in esophageal carcinoma. Am J Surg 182: 197-201

Okano K, Maeba T, Modoguchi A, Ishimura K, Karasawa Y, Izuishi K, Goda F, Usuki H, Wakabayashi H, Maeta H (2003) Lymphocytic infiltration surrounding liver metastases from colorectal cancer. J Surg Oncol 82(1): $28-33$

Seifert JK, Bottger TC, Weigel TF, Gonner U, Junginger T (2000) Prognostic factors following liver resection for hepatic metastases from colorectal cancer. Hepato-Gastroenterology 47: 239-246

Simmonds PC, Primrose JN, Colquitt JL, Garden OJ, Poston GJ, Rees M (2006) Surgical resection of hepatic metastases from colorectal cancer: a systematic review of published studies. Br J Canc 94: 982-999

Steele Jr G, Bleday R, Mayer RJ, Lindblad A, Petrelli N, Weaver D (1991) A prospective evaluation of hepatic resection for colorectal carcinoma metastases to the liver: Gastointestinal Tumor Study Group Protocol 6584. J Clin Oncol 9: 1105-1112

Takahashi S, Inoue K, Konishi M, Nakagouri T, Kinoshita T (2003) Prognostic factors for poor survival after repeat hepatectomy in patients with colorectal liver metastases. Surgery 133: 627-634

Tanaka K, Shimada H, Fujii Y, Endo I, Sekido H, Togo S, Ike H (2004) Pre-hepatectomy prognostic staging to determine treatment strategy for colorectal cancer metastases to the liver. Arch Surg 389: 371-379

Tanigawa N, Amaya N, Matsumura M, Shimomatsuya T (1997) Correlation between expression of vascular endothelial growth factor and tumor vascularity, and patient outcome in human gastric carcinoma. J Clin Oncol 15: 826-832

Thun MJ, Henley SJ, Patrono C (2002) Nonsteroidal anti-inflammatory drugs as anticancer agents: mechanistic, pharmacologic, and clinical issues. J Natl Cancer Inst 94: 252-266

Vidal-Vanaclocha F, Amezaga C, Asumendi A, Kaplanski G, Dinarello CA (1994) Interleukin 1 receptor blockade reduces the number and size of murine B16 melanoma hepatic metastases. Cancer Res 54: $2667-2672$

Vidal-Vanaclocha F, Fantuzzi G, Mendoza L, Fuentes AM, Anasagasti MJ, Martin J, Carrascal T, Walsh P, Reznikov LL, Kim SH, Novick D, Rubinstein M, Dinarello CA (2000) IL-18 regulates IL-1b-dependent hepatic melanoma metastasis via vascular cell adhesion molecule-1. Proc Natl Acad Sci USA 97: 734-739

Xavier P, Belo L, Beires J, Rebelo I, Martinez-de-Oliveira J, Lunet N, Barros $\mathrm{H}$ (2006) Serum levels of VEGF and TNF-a and their association with Creactive protein in patients with endometriosis. Arch Gynecol Obstet 273: $227-231$

Yau M, Kargman S, Lam EC, Kelly CR, Zheng Y, Luk P, Kwong E, Evans JF, Wolfe MM (2003) Inhibition of cycooxygenase-2 by rofecoxib attenuates the growth and metastatic potential of colorectal carcinoma in mice. Cancer Res 63: 586-592 